This is a pre-print published in Bioethics 4, no. 3, 2020, pp 228-234

https://doi.org/10.1111/bioe.12702

\title{
What does Mental Health have to Do with Well-Being?
}

\author{
Simon Keller, Victoria University of Wellington
}

\begin{abstract}
Positive mental health involves not the absence of mental disorder but rather the presence of certain mental goods. Institutions, practitioners, and theorists often identify positive mental health with well-being. There are strong reasons, however, to keep the concepts of well-being and positive mental health separate. Someone with high positive mental health can have low well-being, someone with high well-being can have low positive mental health, and well-being and positive mental health sometimes conflict. But, while positive mental health and well-being are not identical, there is an informative conceptual connection between them. Positive mental health usually contributes instrumentally to the living of a good human life, where a good human life includes (but is not limited to) well-being.
\end{abstract}

KEYWORDS: Positive mental health; well-being; positive psychology; welfare; flourishing. 


\section{What does Mental Health have to Do with Well-Being?}

Simon Keller, Victoria University of Wellington

\section{$\underline{1 . \text { Introduction }}$}

Positive mental health is not the absence of mental disorder, but rather the presence of certain mental goods: certain mental skills, habits, and capacities. ${ }^{1}$ Whether you enjoy positive mental health might depend on whether you are calm and emotionally stable, for example, and on whether you are able to concentrate, whether you can enjoy constructive relationships with others, and whether you take pleasure in the small things in life. For public policy, in various academic fields, and in the popular imagination, positive mental health is of great and arguably increasing significance. Many public health campaigns and "wellness" initiatives aim to promote positive mental health. ${ }^{2}$ Many researchers in the growing field of positive psychology take positive mental health as their central research topic. ${ }^{3}$ The mindfulness movement aims to build positively healthier minds, not only to treat mental illness. ${ }^{4}$ People commonly talk about making

\footnotetext{
${ }^{1}$ Huppert, F. \& So, T.T.C. (2013). Flourishing Across Europe: Application of a New Conceptual Framework for Defining Well-Being. Social Indicators Research, 110, 837-861, see p. 838; and Keyes, C.L.M. (Ed.) (2013). Mental Well-Being: International Contributions to the Study of Positive Mental Health. Dordrecht: Springer, p. 89-90.

${ }^{2}$ See, for example, Bolier, L., Ketelaarb, S.M., Nieuwenhuijsenb, K., Smeetsc, O., Gärtnerb, F.R., \& Sluiter, J.K. (2014). Workplace mental health promotion online to enhance well-being of nurses and allied health professionals: A cluster-randomized controlled trial. Internet Interventions. 1, 196-204; see especially p. 197.

${ }^{3}$ Keyes. C.L.M. (2009). Toward a Science of Mental Health. In C.R. Snyder and S.J. Lopez (Ed.) Oxford Handbook of Positive Psychology (pp. 89-95). Oxford: Oxford University Press. Seligman, M.E.P. \& Csikszentmihalyi, M. (2000). Positive psychology: An introduction. American Psychologist, 55, 5-14; see especially pp. 6, 10.

${ }^{4}$ The UK Mental Health Foundation recommends mindfulness "as a treatment for people with mental ill-health as well as those who want to improve their mental health and wellbeing." Mental Health Foundation (2018, October 19). Mindfulness. Retrieved from https://www.mentalhealth.org.uk/a-to-z/m/mindfulness
} 
lifestyle changes, ending relationships, taking days off work, and leaving Facebook for the sake of their mental health, without having thoughts of avoiding mental disorder.

It is possible to have poor positive mental health while free of mental disorder. Even if you do not have a mental disorder, you might be stressed, tired, and distractible, and hence lacking in positive mental health.

It might also be possible to have good positive mental health while having a mental disorder. Perhaps you suffer from Seasonal Affective Disorder, but you have moved to the tropics and your disorder makes no difference to your life. Or perhaps you have an anxiety disorder, but you have made lifestyle changes and found effective treatments and you keep it well under control. In those cases, you might conceivably enjoy the substantive goods that constitute positive mental health - you might be clear-headed and emotionally stable, perhaps, and you might take pleasure in the small things in life and act constructively within relationships - while yet having an identifiable disorder. You might sensibly say, "I have a mental disorder, but my mental health is great."

Theoretical discussions of mental health often employ several different but inter-related terms. Theorists talk variously of "mental disorder," "mental illness," "mental distress," "languishing," and "flourishing," among many other things. ${ }^{5}$ Nevertheless, one conceptual claim about positive mental health has widespread acceptance and is encoded in some of the most influential definitions of positive mental health: this is the claim that positive mental health is well-being.

The World Health Organization defines positive mental health as "a state of well-being in which an individual realizes his or her own abilities, can cope with the normal stresses of life,

\footnotetext{
${ }^{5}$ See the various terms used in Keyes, op. cit. note 3.
} 
can work productively and is able to make a contribution to his or her community." ${ }^{\circ}$ In positive psychology, an influential definition is given by Felicia Huppert and Timothy So; they say that positive mental health is the same thing as well-being, which in turn consists in competence, emotional stability, engagement, meaning, optimism, positive emotion, positive relationships, resilience, self-esteem, and vitality. ${ }^{7}$ These are representative examples. The identification of positive mental health with well-being is so pervasive that it is often taken for granted. ${ }^{8}$ Writers often use the terms "mental health," "well-being," and "mental well-being" interchangeably. 9

In this paper, I will examine the connection between positive mental health and wellbeing, with the goal of building a better theoretical understanding of positive mental health. I will argue that positive mental health is not identical with well-being, but that there is nevertheless a strong and informative relationship of a different kind between positive mental health and well-being, which any acceptable definition of positive mental health must respect. I will begin by trying to get clearer about the meanings of "well-being" and "positive mental health," then I will give my reasons to think that positive mental health is not well-being. I will finish by trying to say something more constructive about how positive mental health and wellbeing are connected, and about what this means for a theory of positive mental health.

\footnotetext{
${ }^{6}$ World Health Organization. (2014, October 19). Mental health: a state of well-being. Retrieved from http://www.who.int/features/factfiles/mental health/en/

${ }^{7}$ Huppert \& So, op. cit. note 1, pp. 838, 843. See also Keyes, op. cit. note 3.

${ }^{8}$ An exception is Wren-Lewis, S. \& Alexandrova, A. (forthcoming). Mental Health Without Wellbeing. Journal of Medicine and Philosophy. Wren-Lewis and Alexandrova are critical of attempts to identify mental health with well-being, and some of their arguments are similar to those I will offer here. As I note in footnotes 18 and 19, though, the position on which WrenLewis and Alexandrova settle is different from mine.

${ }^{9}$ See the papers collected in (and the title of) Keyes, C.L.M. (Ed.) (2013). Mental Well-Being: International Contributions to the Study of Positive Mental Health. Dordrecht: Springer.
} 


\section{The concepts of well-being and positive mental health}

As the term is used in the philosophical literature, something increases your "well-being" if it makes you better off in the most fundamental sense. A measure of well-being is a measure of how well a life goes for the person who lives it. Your well-being is identical with your "welfare" and with what makes your life go best. If something advances your well-being, as philosophers understand the term, then it advances your best or true or real interests. ${ }^{10}$

The term "well-being" is sometimes used more narrowly. People sometimes speak of “economic well-being" or "cultural well-being," for example, and theorists sometimes distinguish "hedonic," "subjective," and "eudaimonic" well-being. ${ }^{11}$ When you think about "well-being" in ordinary life - or when you imagine the "well-being" section in a bookstore you might think not of the whole of life, but instead only of parts of it: perhaps those concerning yoga, meditation, and smoothies.

Nevertheless, there is conceptual common ground on what we mean when we conceive of well-being as concerning a person's welfare or true best interests, and on what theorists mean when they identify well-being with positive mental health. Your well-being is a matter of how well things go for you, and while the exact nature of well-being is disputed, it has centrally to do with being happy, being content, and relating well to those around you and the world at large. That intuitive conception of well-being is enough to get us started.

Mental health, too, can be understood in a variety of ways and is construed differently within different cultures and contexts. There is a notion of mental health that the general topic of the health of the mind, including mental "illness," "disease," "disorder," and "sickness", and

${ }^{10}$ See Bradley, B. (2015). Well-Being, Cambridge: Polity Press; and Fletcher, G. (2016). The Philosophy of Well-Being: An Introduction. Abingdon: Routledge.

${ }^{11}$ Keyes, op. cit. note 3, pp. 90-91. 
mental "health" in its various forms. (That is what I will refer to when I use the unadorned term "mental health" here.) Then there is "mental health" construed as the absence of mental disease or disorder ${ }^{12}$; and there is "positive mental health," the topic of this paper.

On all conceptions, mental health is a condition of the mind. To evaluate a person's mental health is to evaluate her mental states: her feelings, emotions, beliefs, desires, addictions, drives, motives, neuroses, fears, ambitions, and so on. If something does not concern the mind, then it does not concern mental health.

When we talk about positive mental health, then, we need to use the language of the mental, at least in the first instance. We need to talk about feelings, beliefs, emotions, and so on, and not only about - for example - neurons, lesions, and chemical imbalances in the brain. Mental states may supervene upon or be in some other sense reducible to brain states. It may be that whenever a person has a healthy (or unhealthy) mind, she also has a healthy (or unhealthy) brain, and it may be that the best ultimate explanations of our states of mental health refer directly to states of the body. But still, if we are to make sense of mental health, then we need to make sense of the health of emotions, feelings, beliefs, and other states of mind, whatever the deeper metaphysical nature of such states may be. ${ }^{13}$

That is one reason why it can seem natural to identify positive mental health with wellbeing. To say that someone has healthy emotions, healthy beliefs, healthy desires, healthy feelings - that can sound just like saying she has a mind in which things are going well. And saying that things are going well in her mind sounds just like saying that things are going well

${ }^{12}$ See the style of definition in Boorse, C. (1976). What a theory of mental health should be. Journal for the Theory of Social Behavior, 6, 61-84.

${ }^{13}$ See the discussion in Arpaly, N. (2005). How it is not "Just Like Diabetes": Mental Disorders and the Moral Psychologist. Philosophical Issues, 15, 282-298, especially pp. 282-290. 
for her, and hence that she enjoys well-being. While positive mental health surely has some connection with well-being, however, I want to argue that the two are not, in the end, identical.

\section{Positive mental health as well-being: some problem cases}

According to the World Health Organization, again, positive mental health consists in well-being, and a person who enjoys well-being "realizes his or her own abilities, can cope with the normal stresses of life, can work productively and is able to make a contribution to his or her community." 14

It is possible for a person to be unable to work productively or to contribute to her community because she is excluded. Imagine a person who cannot work productively because she is an immigrant and does not have a work visa. Imagine a person who is unable to get a job because she is considered too old, or who does not have access to transport and other support that would allow her to carry out volunteer work or make other contributions to her community. These are people who fail to meet the WHO's definition of positive mental health, but their problems are not to do with the condition of their minds. That a person is excluded from productive work by her immigration status or age or lack of access to transport and other support does not mean that she lacks mental health: her mental states are not to blame.

According to Huppert and So, again, positive mental health is well-being, which in turn consists in competence, emotional stability, engagement, meaning, optimism, positive emotion, positive relationships, resilience, self-esteem, and vitality. ${ }^{15}$

\footnotetext{
${ }^{14}$ World Health Organization, op. cit. note 5.

${ }^{15}$ Huppert \& So, op. cit. note 1, pp. 838, 843.
} 
Suppose that you do not enjoy any positive relationships with other people. Suppose that the reason why is that you live on a remote scientific station in Antarctica, and the few people who live there with you are all truly toxic; suppose that you quite sensibly choose to stay away from them and to live a solitary life. You may then face problems in life, but you do not necessarily face problems with your mental health. It is not because of you or your mind that you fail to enjoy positive relationships. It is not because there is anything unhealthy about your mental skills, habits, and capacities that you fail to meet Huppert and So's definition of positive mental health.

The two representative definitions of positive mental health, then, face counterexamples. In identifying positive mental health with well-being, they make it depend upon factors that do not necessarily have anything to do with the condition of a person's mind.

The counterexamples, as I have expressed them, depend upon the respective ways in which the WHO and Huppert and So characterize well-being. It could be that the problem is not with the identification of positive mental health with well-being, but rather with the particular pictures of well-being embedded in these two definitions. Behind the counterexamples, though, are conceptual points that present objections to any view that takes positive mental health and well-being to be the same thing.

\section{$\underline{4 .}$ Positive mental health without well-being}

There are causes of poor well-being that do not have to do with the condition of the mind. To put it another way: there are factors that bear upon well-being but do not bear upon mental health. 
Some of the relevant factors have to do with the person's external circumstances. Think about the respects in which circumstances can reduce your quality of life. Imagine a person who has devoted her life to building a school and imagine that the school has been destroyed by an earthquake before it is completed. Imagine also that the person has lost her family and closest friends in a series of accidents, and that she has been wrongly accused of a serious crime and faces time in jail and a long battle to clear her name. On any theory of well-being, it is easy to imagine that the person in the example now has low well-being. She has much to be sad about; her major projects have failed; her life is not going well at all. But nothing in the description of the case reveals anything directly about her mental health. It is possible, consistently with the example as described, that she deals with her misfortune in the most mature and constructive manner possible. Her emotions and feelings and ways of dealing with her situation may be as healthy as can be.

Internal factors, too, can cause a person to have low well-being without having to do with her mental health. Most people care about things other than their own well-being and sometimes make decisions and pursue projects in response to values other than their own best interests. Your high positive mental health might enable you better to pursue a project that reduces your well-being. Consider some examples.

Suppose that you decide to devote yourself to the care of a sick relative. You might make that decision while knowing that caring for your relative will be unpleasant, bring few rewards, and require you to sacrifice personal and professional opportunities. If you are resilient, focused on your goals, patient, and able to avoid self-pity, then you may be better able to stick with your project of caring for your sick relative, with all the personal sacrifice it entails. Your strong positive mental health may enable you all the better to sacrifice your own well-being. 
Suppose that you choose to become an aid worker in a distant part of the world. Suppose that you know that the work will be difficult and will take you far from your friends and family. You know that you are likely to get very sick at times and that you will lose some of your friendships and some valuable professional opportunities. You make the decision deliberately, choosing to sacrifice your own interests to pursue a cause that you value. The fact that you have good positive mental health - that you show persistence, self-confidence, strength of will, and good planning - may help you to carry out your decision all the more effectively. Your strong positive mental health, in such a case, could be one of the causes of your coming to have lower well-being.

\section{Well-being without positive mental health}

Positive mental health, then, is not sufficient for well-being. There are good reasons to think that it is not necessary either. People with poor positive mental health sometimes enjoy enviable levels of well-being.

The features of a mind that constitute poor positive mental health might, through good luck or odd circumstances, allow a person to achieve higher levels of well-being. Earlier, I mentioned cases in which a person might have high positive mental health even while living with a mental disorder. In other cases, a person might clearly have low positive mental health, in certain important respects, yet her low positive mental health might make no difference to her quality of life and might even help make her life better.

Impulse control, for example, is plausibly an element of positive mental health. But under some odd circumstances, your uncontrolled impulses might lead you to do things that make your life better. Perhaps you impulsively eat a kind of food that turns out to be very good for you. 
Perhaps you have an uncontrollable attraction to certain people, and those people turn out to be the ones with whom you can share the most rewarding relationships. With your inability to moderate your impulses, you are not an exemplar of positive mental health, but you might enjoy high well-being regardless.

You might suffer from a social phobia, becoming panicky and anxious when in the presence of large groups of people. As a result, you might organize your life around avoiding crowds, and this might work out very well for you. You might be perfectly happy interacting with only a few close friends, you might thrive while working in a profession that allows you to be alone most of the time, and you might find great pleasure in engaging in solitary leisure activities. You would not be someone who enjoys high positive mental health: you lack a central mental capacity and you need to arrange your life so as to avoid large groups. But nevertheless, compared to the rest of us, you might enjoy high well-being. You might be as happy and content and fulfilled as can be.

Pushing the point further, imagine a person who suffers from alcoholism and who knows that his addiction will always be with him; he will always need to manage his addiction and will never have a healthy relationship with alcohol. He attends regular support-group meetings and counselling sessions. He avoids pubs and bars, forcing himself always to be home and in bed early. As a result, he is happier than most of us will ever be. He develops deep friendships with the other members of his support group, and in fact it is there that he meets the love of his life. Through his counselling sessions he learns a great deal about himself. With his newfound time and energy in the mornings, he takes up a sport, spends more time with his family, and performs better at his job. Looking at his life, he may say not only that he has flourished despite his alcoholism, but also that his alcoholism, indirectly, has brought him the things that have made 
his life so wonderful. His life is shaped by his mental health problem - he remains an alcoholic but his deficit in positive mental health has made his life better, not worse.

\section{Choosing between positive mental health and well-being}

Positive mental health sometimes competes with well-being, and sometimes, a person places too much importance upon her positive mental health, at the expense of her well-being. Imagine someone who refuses ever to travel, because she finds travel too stressful and judges it to be bad for her mental health. She gets anxious when dealing with all the planning, she is fearful of flying, she worries about her house when she is away, she sleeps badly when not in her own bed, and she gets irritable and short-tempered when she cannot eat and exercise at exactly the times she prefers. She might be correct to think that it is better for her mental health to stay home and avoid travel; at home she is calmer, more rested, more confident, and more controlled. But her decision may also deprive her of many sources of joy and many profound experiences; some of the best things in life are accompanied by worry, fear, tiredness, or irritation. It would be better for her, we can imagine, if she were to focus more on having a rich and rewarding life and less on tending to her mental health.

There are many similar imaginable cases. You may know someone who never stays up late because he wants to have a fresh mind for his meditation session in the morning, or who will not send his work to refereed journals because criticism hurts his self-confidence, or who will not spend time with his grown siblings because it brings back feelings of inadequacy from his childhood. Such a person, again, might make quite correct and understandable judgments about how best to maintain his positive mental health, but in failing to accept setbacks to his mental 
health he may miss out on experiences that would enhance his well-being. Positive mental health is worth caring about, but not to the exclusion of everything else.

\section{$\underline{\text { 7. From conceptual arguments to practical consequences }}$}

I have tried to show that it is possible for a person to have low well-being but high positive mental health, to have low positive mental health but high well-being, and to place too much importance on her positive mental health at the expense of her well-being. My arguments depend upon imagined cases, most of which involve unusual people or sets of circumstances. The cases are intended to make the point, however, that there is a significant conceptual difference between positive mental health and well-being. Well-being and positive mental health might usually go together, but sometimes they come apart. They are two different things. We should not define positive mental health as well-being.

The point bears upon practical issues. Where well-being and positive mental health are construed as the same thing, it is more likely that any form of unhappiness, or anything that sets back the quality of a person's life, will be viewed as a mental health issue. ${ }^{16}$ This can have consequences for how a person views her own situation and for what kinds of interventions she seeks and is offered. If any setback to well-being is construed as a mental health problem, then it is easy to think that the fault for low well-being lies within the person's mind, or that interventions should focus upon the person's feelings and attitudes, rather than upon - for example - the ways in which she is treated by others or the social context within which her suffering is caused.

\footnotetext{
${ }^{16}$ See Wren-Lewis \& Alexandrova op. cit. note 8, section 5.
} 
In addition, if positive mental health is identified with well-being, then forms of poor mental health can be naturally construed as forms of mental suffering. Some public health bodies, in fact, suggest that talk of "mental distress" should replace all talk of mental health problems, and of mental illness and disorder. ${ }^{17}$ Accepting that there is a gap between positive mental health and well-being, however, allows us to envisage forms of poor mental health that do not cause distress, and that may even, under some circumstances, relieve it. It is one thing to be distressed; it is another thing to have a mental health problem. There is good practical reason to keep talk of poor mental health and talk of distress distinguished.

\section{$\underline{\text { 8. The instrumental value of positive mental health }}$}

If positive mental health is not the same thing as well-being, then why care about positive mental health? Positive mental health obviously matters, but once it is detached from well-being, it is not clear why it matters. If we are not to define positive mental health as well-being, then we face the challenge of saying why positive mental health is nevertheless something to value. In closing the paper, I will offer some suggestions about how positive mental health and well-being are related, suggesting that the relationship is of a form that makes positive mental health valuable, and valuable partly for its contribution to well-being, even though positive mental health and well-being are not the same.

As first observation, note that something can be very valuable without being valuable for its own sake. Education, for example, is very valuable, and its value comes, at least largely, from the good things to which it usually leads. Education is valuable because it leads to wisdom and

\footnotetext{
${ }^{17}$ See the language used in Kvalsvig, A. (2018). Wellbeing and mental distress in Aotearoa New Zealand: Snapshot 2016. Wellington: Health Promotion Agency.
} 
understanding, gives people greater opportunities for living well, and produces various other social goods. Food, too, is very valuable, but not (or not only) for its own sake. Food is valuable for the good things it can give us: things like nourishment and pleasure. Education and food, then, have instrumental value. They are valuable for what they produce.

In the same way, positive mental health can be very valuable, but valuable for what it (usually) produces. I have given several cases in which positive mental health does not lead to well-being or in which well-being is enjoyed without positive mental health. The existence of those cases does not detract, however, from the wider truth that usually, a person who has greater positive mental health is more likely to live a life high in well-being. ${ }^{18}$

The kinds of goods ordinarily associated with positive mental health, indeed, appear to be valuable largely because they tend to improve people's lives. If you are calm and thoughtful, keep things in perspective, participate constructively in relationships, and can concentrate and make plans and work patiently towards your goals, then you will probably be happier and more successful and live the kind of life you most want for yourself. None of this is guaranteed by positive mental health, but it is made more likely. Even if positive mental health is not wellbeing, there is good reason to think that it is instrumentally connected with well-being and that it is valuable partly for that reason. That positive mental health should have great instrumental value, partly by virtue of the contribution it usually makes to well-being, is quite consistent with its sometimes failing to produce well-being and with well-being's sometimes existing in the absence of positive mental health.

\footnotetext{
${ }^{18}$ Wren-Lewis and Alexandrova op. cit. note 8 also take mental health to have an instrumental connection with well-being (see their sections 6 and 7). They suggest that mental health is necessary but not sufficient for well-being; I have argued that it is neither necessary nor sufficient.
} 


\section{The good human life}

As a second observation, note that there is a difference between a life that is rich in wellbeing and a life that is, in the broadest sense, good. A life rich in well-being goes well for the person who lives it. A good life goes well not only for the person who lives it but also from a wider evaluative point of view. Your life could be good not only because it brings happiness to

you, but also because it brings happiness to others, or because it manifests various other values. ${ }^{19}$

The nature of the good human life is a topic of long-standing debate. Is a good life a life of action, a life of contemplation, a life of love and compassion, a life of authenticity, or a life of drama and beauty? A good life might be a life that is ethical or artistic; it might be a life that contributes to human knowledge, is lived in the service of others, manifests courage and integrity, or is built around an unflinching regard for truth.

What matters for present purposes is that while well-being is an element of the good life, it is not the only element. Not all the things that make a life good make it go well for the person who lives it. In asking whether you live a good human life, we might ask about how your life goes for you, but also about what other values it embodies and serves. ${ }^{20}$

${ }^{19}$ Wren-Lewis \& Alexandrova op. cit. note 8 define mental health not through its instrumental contribution to living a good life, but rather through its tendency to help a person pursue the good life as she conceives it.

${ }^{20}$ On some Aristotelian conceptions of happiness and on some conceptions of "eudaimonic wellbeing," a person benefits, as a matter of definition, from flourishing as a human. Human flourishing conceivably involves living morally and rationally, and perhaps living a life of beauty or authenticity. Those who accept such a conception of well-being may not see much of a difference between well-being and the good human life and may be happy to use the term "wellbeing" to cover all the goods that count as elements of a good human life. Such theorists may then be able to maintain that positive mental health is valuable simply for its contribution to well-being. That contribution would still be instrumental and contingent, however, and wellbeing would be conceived in very expansive terms - terms so expansive that the distinction between their conception of well-being and my conception of the good human life would become 
Positive mental health, I want to suggest, is valuable because it has a strong instrumental connection with the good human life. You are more likely to live a good human life if you have positive mental health. Positive mental health does not guarantee a good life, and you may be able to live a good life without it, but usually, it makes the good life more attainable.

Well-being, again, is an element of the good life, but it is not the only element, and positive mental health can be valuable because it contributes to other things that make a human life good. Returning to my earlier examples, having positive mental health may help you more effectively to devote yourself to caring for a sick relative or to living as an aid worker in a distant part of the world; it may thereby help you to live a better life, even if a life that is good for others rather than for you. Positive mental health, in such cases, is valuable because it makes your life better in certain respects, even if not by increasing your well-being.

\section{Possibilities for a theory of positive mental health}

On my view, then, positive mental health contributes, usually but not always, to the living of a good human life. In light of this suggestion, there are two possibilities for building a theory of positive mental health.

The first possibility is to identify mental health with a further phenomenon, and then to show that that phenomenon is instrumentally connected with the good human life. For example, we could say that positive mental health is good mental functioning, meaning that a healthy human mind is one that performs certain designated functions - perhaps those that advance survival and reproduction; and we could try to show that a person whose mind performs its

merely terminological. For a discussion of Aristotelian approaches to happiness, see Annas, J. (1995). The Morality of Happiness. Oxford: Oxford University Press. 
designated functions is more likely to live a good human life. ${ }^{21}$ As another example, we might say that positive mental health consists in rationality, meaning that a mentally healthy person thinks and acts in accordance with reason, and then try to show that a person is more likely to live a good life if she is rational. ${ }^{22}$

The second possibility is to define positive mental health directly through its instrumental connection with the good life. We could say that positive mental health consists in whichever mental skills, dispositions, and capacities make a person more likely to live a good human life, in one or other of its forms. To give some examples, perhaps we could show that such things as patience, the ability to concentrate, the ability to delay gratification, emotional stability, compassion, self-awareness, and the habit of taking pleasure in the small things in life all make a person more likely, on the whole, to live a good life. Perhaps that is simply what it means for them to be components of positive mental health.

\section{Conclusion}

Insofar as there is a prevailing theory of positive mental health, it is that positive mental health is the same thing as well-being. My main goal in this paper has been to show that the identification of positive mental health with well-being is mistaken. Considering some uncontroversial conceptual truths about well-being and some standard judgments about positive mental health, there are many easily imaginable cases in which positive mental health and wellbeing come apart. I have also tried to say something about where a better theory of positive mental health might be found. Positive mental health is valuable, I have suggested, not because it

${ }^{21}$ See the definition of disease in Boorse, op. cit. note 12, pp. 62-63.

${ }^{22}$ For a view that applies this thought to an analysis of mental disorder, see Graham, G. (2010). The Disordered Mind. Abingdon: Routledge. 
is or guarantees well-being, but because it is instrumentally connected with the living of a good human life, where the good human life has well-being as one of its parts. There is a significant and consequential relationship between positive mental health and well-being, but it is a more complicated relationship than simple identity.

\section{Acknowledgements}

I am grateful for helpful comments and research assistance from Snita Ahir-Knight, and for comments from Felicia Huppert, Neil Levy, Philip Gerrans, Justin Systma, Nicholas Agar, Edwin Mares, and two referees for this journal. I am also grateful for a fellowship from the Center for Advanced Studies at Ludwig-Maximilians-Universität München, where much of this paper was written, and for the support of Victoria University of Wellington. 